\title{
A CONSTITUCIONALIZAÇÃO DO MEIO AMBIENTE NO BRASIL
}

\author{
Fúlvia Leticia Perego Silva; Munir Jorge Felício
}

Universidade do Oeste Paulista-UNOESTE, Mestrado em Meio Ambiente e Desenvolvimento Regional - MMADRE, Presidente Prudente, SP. E-mail: fulvialeticia.adv@uol.com.br

\section{RESUMO}

As constituições federais que antecederam a de 1988 não se preocuparam com a tutela jurídica ambiental, vez que, até então, os recursos naturais eram considerados inesgotáveis, utilizados, por isso, de forma desregrada, sob um enfoque econômico-utilitarista. O objetivo desse estudo é verificar a evolução histórica da proteção jurídica ambiental nas constituições brasileiras, trazendo o fenômeno da constitucionalização ambiental como um direito fundamental. Utilizou-se como metodologia a lógica dedutivo-indutiva, através de pesquisa bibliográfica ancorada no método histórico-empírico-analítico, partindo-se de uma abordagem geral das constituições federais para uma abordagem particular do atual ordenamento jurídico constitucional. Conclui-se que a atual Carta Magna, diferentemente das anteriores, criou um direito fundamental a um meio ambiente ecologicamente equilibrado, como bem coletivo essencial ao bem estar do povo, fonte de direitos de titularidades igualmente coletivas, base da preservação da natureza e garantia de equilíbrio ecológico para as atuais e futuras gerações.

Palavras-chave: Constitucionalização. Meio Ambiente. Proteção Ambiental. Constituição Federal. Direito Fundamental.

\section{ENVIRONMENTAL CONSTITUTIONALIZATION IN BRAZIL}

\begin{abstract}
The federal constitutions prior to 1988 were not concerned with environmental legal protection, since, until then, natural resources were considered inexhaustible, used, therefore, of disorderly manner under an economic and utilitarian approach. The aim of this study is to verify the historical evolution of environmental legal protection in Brazilian's constitution, bringing the phenomenon of environmental constitutionalization as a fundamental right. It was used as a methodology the deductive-inductive logic, through bibliographic search anchored in the historical-empiricalanalytical method, starting with an overview of the federal constitutions for a particular approach of the present constitutional law. It concludes that the current Constitution, unlike the previous ones, created a fundamental right to an ecologically balanced environment, as well collective essential to the welfare of the people, source entitlements of rights equally collectives, basis of preservation of nature, and guarantee of ecological balance for present and future generations.

Keywords: Constitutionalization. Environment. Environmental Protection. Federal Constitution. Fundamental Right.
\end{abstract}


INTRODUÇÃO

A Carta Constitucional de 1988 estabeleceu diretrizes fundamentais para a proteção e preservação do meio ambiente, inaugurando uma nova ordem pública ambiental constitucionalizada, visando através de seus preceitos equilibrar a sadia qualidade de vida e os recursos naturais. A proteção ambiental assume, então, grande importância como forma de garantir a sobrevivência da humanidade, onde todos passam a ter o direito ao meio ambiente ecologicamente equilibrado, sendo erigido à categoria de direito fundamental.

Entretanto, a história nos mostra que as Constituições anteriores a de 1988 nunca mencionaram a expressão 'meio ambiente', demonstrando que os recursos naturais sempre foram utilizados para satisfazer o desejo humano de forma desregrada, irrestrita e ilimitada, sob enfoque econômico e utilitarista, sem nenhuma preocupação com sua escassez e degradação ambiental.

Assim é de suma importância a investigação proposta, em razão de que é necessário conhecer o passado com seus erros e acertos, para que a sociedade possa ter maior maturidade no enfrentamento das questões ambientais, buscando sempre o verdadeiro alcance da norma jurídica constitucional ambiental.

O presente artigo tem por objetivo, portanto, verificar a evolução histórica da proteção jurídica ambiental nas Constituições Brasileiras, trazendo o fenômeno da constitucionalização ambiental como um direito fundamental.

\section{METODOLOGIA}

Utilizou-se como metodologia a lógica dedutivo-indutiva, através de pesquisa bibliográfica ancorada no método histórico-empírico-analítico, partindo-se de uma abordagem geral das constituições federais para uma abordagem particular do atual ordenamento jurídico constitucional no âmbito da proteção ambiental, possibilitando a compreensão da historicidade de como o meio ambiente foi tratado nas constituições brasileiras até os dias atuais e em que momento foi erigido à categoria de direito fundamental.

\section{DISCUSSÃO}

No Brasil, a proteção ambiental constitucional somente ocorre com a promulgação da Constituição Federal de 1988. As Constituições que a precederam não se preocuparam com a tutela ambiental de forma específica e globalizante. Ao analisar a historicidade das Constituições pátrias, Milaré (2011, p. 183) ressalta que, antes da Carta Magna de 1988, "nem mesmo uma vez 
foi empregada a expressão meio ambiente, dando a revelar total inadvertência, ou, até, despreocupação com o próprio espaço em que vivemos."

As análises de Milaré (2011) são reforçadas com as de Antunes (2013, p. 62), quando confirmam a inexistência da defesa dos recursos naturais anteriores a 1988, afirmando que "os constituintes anteriores não se preocupavam com a conservação dos recursos naturais ou com a sua utilização racional". Thomé (2012, p. 115-116) ensina que "os recursos naturais eram tidos como recursos econômicos a serem explorados e a sua abundância tornava inimaginável a necessidade de algum tipo de proteção." A defesa unívoca desses três doutrinadores indica a importância de se conhecer de que forma eram considerados os recursos naturais nas constituições que antecederam a de 1988.

A Constituição Imperial de 1824 não fez qualquer referência aos recursos naturais. Antunes (2013, p. 63) menciona ser curioso, no entanto, que, "na ocasião de sua promulgação, o País era essencialmente exportador de produtos primários não manufaturados e, portanto, inteiramente dependente dos bens de sua natureza". A concepção predominante era, segundo o mesmo autor, a de que o Estado não devia se envolver nas atividades econômicas e consequentemente não cabia à Constituição traçar qualquer perfil de uma ordem econômica constitucional (ANTUNES, 2013, p. 63). Esta Constituição, no artigo 179, n. XXIV, apenas cuidava da proibição de indústrias contrárias à saúde do cidadão (MILARÉ, 2011, p. 183).

A Constituição Federal de 1891, que sucedeu o Império do Brasil, refletiu a mudança do regime político, cuja característica essencial foi o estabelecimento de um regime republicano e federativo. Milaré (2011, p. 183) destaca que o "texto republicano de 1891 atribuía competência legislativa à União para legislar sobre as suas minas e terras (artigo 34, n. 29)". Destaca Antunes (2013, p. 64) que:

Em tese, aos Estados estava reservada a competência para legislar sobre as minas e terras que não pertencessem à União. Era um dispositivo extremamente genérico e insuficiente para definir atribuições. Aparentemente, questões que não dissessem respeito às minas e terras da União estavam sob a competência legislativa dos Estado-Membros.

A Constituição Federal de 1934 acabou sendo fruto da Revolução de 1930 e da Revolução Constitucionalista de 1932, ocorrida em São Paulo, que segundo Antunes (2013, p. 64), "dentro do espírito da época, tinham características intervencionistas na ordem econômica e social”. Milaré (2011, p. 183) aponta que a referida Carta Magna "dispensou proteção às belezas naturais, ao patrimônio histórico, artístico e cultural (artigos 10, III, e 148); conferiu à União competência em 
matéria de riquezas do subsolo, mineração, águas, florestas, caça, pesca e sua exploração (art. 5으, $X I X, j) "$.

De alguma forma, para Antunes (2013, p. 65) essa Constituição estimulou o desenvolvimento de uma legislação infraconstitucional que se preocupou com a proteção do meio ambiente dentro de uma abordagem de conservação de recursos econômicos, como é o caso do Código de Águas de 1934 (Decreto 24.643 /34), cujos objetivos primordiais estavam relacionados à produção de energia elétrica. O mesmo se pode dizer em relação ao antigo Código Florestal (Decreto no 23.793/34), que buscou estabelecer mecanismos para a utilização industrial das florestas.

A Constituição de 1937 manteve-se no mesmo padrão da Constituição de 1934, tendo se preocupado também com a proteção dos monumentos históricos, artísticos e naturais, bem como das paisagens e locais especialmente dotados de natureza (art. 134); incluiu entre as matérias de competência da União legislar sobre minas, águas, florestas, caça, pesca e sua exploração (art. 16, XIV); cuidou ainda da competência legislativa sobre subsolo, águas e florestas no art. 18, $a$ e $e$, onde igualmente tratou da proteção das plantas e rebanhos contra moléstias e agentes nocivos, conforme menciona Milaré (2011).

A Constituição de 1946, sob o regime democrático, "não alterou substancialmente as competências legislativas da União em temas referentes à infraestrutura e, consequentemente, ambientais" (Antunes, 2013, p. 65). Milaré (2011, p. 183) destaca que a referida constituição, “além de manter a defesa do patrimônio histórico, cultural e paisagístico (art. 175), conservou como competência da União legislar sobre normas gerais de defesa da saúde, das riquezas do subsolo, das águas, florestas, caça e pesca".

A Constituição de 1967 se constituiu durante o regime militar que se instalou em 10 de abril de 1964, "com a exacerbação dos poderes do Executivo Federal, que passou a exercê-los de forma discricionária e autoritária" (Antunes, 2013, p. 65). A referida Constituição insistiu na necessidade de proteção do patrimônio histórico, cultural e paisagístico (art. 172, parágrafo único). Atribuiu à União, dentre outras, a competência para organizar a defesa permanente entre as calamidades públicas, especialmente a seca e as inundações, nos termos do artigo 8o, XII. Competia também à União explorar, diretamente ou mediante autorização ou concessão, os serviços e as instalações de energia elétrica de qualquer origem ou natureza, mantendo a característica de que a infraestrutura era uma matéria federal. Quanto à competência legislativa propriamente dita, a Carta de 1967 estabelecia que a União era dotada dos seguintes poderes legislativos, conforme relaciona Antunes (2013, p. 65-66): 
(i) direito agrário; (ii) normas gerais de segurança e proteção da saúde; (iii) águas e energia elétrica; (iv) jazidas, minas, e outros recursos minerais;(v) metalúrgica;(vi) floresta, caça e pesca; (vii) regime dos portos e da navegação de cabotagem, fluvial e lacustre.

A Constituição de 1969 surgiu da Emenda Constitucional no 1, outorgada por uma Junta Militar que manteve os termos daquilo que foi acima citado. Houve, segundo Antunes (2013, p. 66), entretanto, "uma pequena mudança no que diz respeito às competências legislativas em relação à energia, que foi subdividida em elétrica, térmica, nuclear ou de qualquer natureza". Milaré (2011, p. 184) menciona a introdução do vocábulo ecológico em textos legais, como se deu no art. 172 ao dispor que “a lei regulará, mediante prévio levantamento ecológico, o aproveitamento agrícola de terras sujeitas a intempéries e calamidades e que o mau uso da terra impedirá o proprietário de receber incentivos e auxílio do Governo".

Pelo que se observa de um modo geral, até a Constituição de 1988 as competências constitucionais em matéria ambiental mereceram tratamento apenas tangencial, tendo o constituinte como principal preocupação a infraestrutura para o desenvolvimento econômico. Segundo Antunes (2013, p. 66), "o aspecto que foi privilegiado, desde que o tema passou a integralizar a ordem jurídica constitucional, foi o de meio de produção".

\section{A CONSTITUIÇÃO FEDERAL DE 1988}

A Constituição Federal de 1988 se diferenciou totalmente das demais constituições, que apenas abordavam os recursos naturais sob o enfoque econômico e utilitarista, deixando de tratar os recursos naturais sob a ótica protecionista. Para ressaltar a importância da reparação, proteção e prevenção, Milaré (2011) a denomina de "constituição verde", pois ela foi a primeira a tratar de forma direta o meio ambiente, insistindo na sua valorização axiológica.

A Carta Magna de 1988 inovou, superando, segundo Trennepohl (2009, p. 80), "inclusive, as Constituições estrangeiras mais recentes (Bulgária, art. 31; ex-URSS, art. 18; Portugal, art. 66; Espanha, art. 45) no que concerne à proteção ambiental, erigindo ao patamar constitucional um tema ainda pouco difundido na doutrina e jurisprudência nacional". Além de ser dotada de um capítulo próprio para as questões ambientais, ao longo de diversos outros artigos trata das obrigações da sociedade e do Estado brasileiro para com o meio ambiente.

O Brasil, seguindo a tendência mundial, após a Declaração de Estocolmo (1972), realizou a constitucionalização do meio ambiente, ocupando o segundo grupo de países que promulgou Cartas Magnas com a tutela ambiental. Os países do primeiro grupo que se libertaram de 
ditaduras para se adequarem à nova ordem mundial na defesa do meio ambiente foram a Grécia (1975), Portugal (1978) e Espanha (1978). No entendimento de Milaré (2011, p. 184):

(...) o Texto Supremo captou com indiscutível oportunidade o que está na alma nacional - a consciência de que é preciso aprender a conviver harmoniosamente com a natureza -, traduzindo em vários dispositivos aquilo que pode ser considerado um dos sistemas mais abrangentes e atuais do mundo sobre a tutela do meio ambiente.

Para Antunes (2013, p. 66), “a Constituição de 1988 não desconsiderou o Meio Ambiente como elemento indispensável e que servirá de base para o desenvolvimento da atividade de infraestrutura econômica". O referido autor enfatiza que com o advento da Constituição Federal de 1988 houve um aprofundamento das relações entre o Meio Ambiente e a infraestrutura econômica, buscando estabelecer um mecanismo mediante o qual as naturais tensões entre os diferentes usuários dos recursos ambientais possam ser amenizadas dentro de uma perspectiva de utilização racional.

Thomé (2012, p. 117) destaca "a substituição do paradigma da legalidade ambiental pelo paradigma da constitucionalidade ambiental, o que inaugura uma ordem pública ambiental constitucionalizada". Essa constitucionalização, segundo esse mesmo autor, por consequência, repercute diretamente na atuação do Poder Público e de toda a coletividade, na medida em que Ihes é dirigida a obrigação de implementação do principio do desenvolvimento sustentável.

\section{MEIO AMBIENTE ECOLOGICAMENTE EQUILIBRADO COMO DIREITO FUNDAMENTAL}

O constituinte brasileiro estabeleceu que "todos têm direito ao meio ambiente ecologicamente equilibrado, bem de uso comum do povo e essencial à sadia qualidade de vida, impondo-se ao Poder Público e à coletividade o dever de defendê-lo e preservá-lo para as presentes e futuras gerações" (art. 225, caput, da CF). O alcance da referida norma-matriz é de grande importância para a adoção de um sistema constitucional de proteção ao meio ambiente, tendo-se institucionalizado o direito ao meio ambiente ecologicamente equilibrado e sadio como um direito fundamental do indivíduo, conforme menciona Milaré (2011, p. 189):

Cria-se um direito constitucional fundamental ao meio ambiente ecologicamente equilibrado. Como todo direito fundamental, o direito ao ambiente ecologicamente equilibrado é indispensável. Ressalte-se que essa indisponibilidade vem acentuada na Constituição Federal pelo fato de mencionar-se que a preservação do meio ambiente deve ser feita no interesse não só das presentes, como igualmente das futuras gerações. 
Para Thomé (2012, p. 116) “os grandes princípios ambientais são içados ao patamar constitucional, assumindo um posto iminente ao lado das grandes liberdades públicas e dos direitos fundamentais". Leite e Ayala (2012, p. 86), se referindo ao caput do artigo 225, afirmam que "apesar de não estar inserida no capítulo dos direitos e deveres individuais e coletivos, não é possível afastar o seu conteúdo de direito fundamental", e ainda, "o direito fundamental ao meio ambiente ecologicamente equilibrado se insere ao lado do direito à vida, à igualdade, à liberdade, caracterizando-se pelo cunho social amplo e não meramente individual”.

Resta evidente o surgimento dos direitos de titularidade coletiva, denominados de direitos fundamentais de terceira dimensão, pois consagram o princípio da solidariedade, onde se destaca, segundo Belchior (2011, p. 83), “o meio ambiente ecologicamente equilibrado, uma saudável qualidade de vida, progresso, autodeterminação dos povos e outros direitos difusos ${ }^{1 "}$. São direitos que transcendem o individual e o coletivo e, segundo Sarlet $(2012,48)$ :

Os direitos fundamentais da terceira dimensão, também denominados de direitos de fraternidade ou de solidariedade, trazem como nota distintiva o fato de se despenderem, em princípio, da figura do homem-indivíduo como seu titular, destinando-se à proteção de grupos humanos (família, povo, nação), e caracterizando-se, consequentemente, como direitos de titularidade coletiva ou difusa.

Nesse sentido, o meio ambiente como direito fundamental possui dupla dimensão: não pode ser pensado apenas do ponto de vista individual ou privado, deve também ser considerado a partir do ponto de vista da coletividade por se tratar de direito assegurado às presentes e futuras gerações. Assim, a obrigação correspondente a esse direito, ou seja, de proteção ambiental, não é apenas um dever jurídico do Estado, mas também de todos os membros da comunidade.

\section{CONCLUSÃO}

A escassez dos recursos naturais, somada ao crescimento desordenado da população mundial e à intensidade dos impactos ambientais, gera o conflito da sustentabilidade dos sistemas econômico e natural, tornando o meio ambiente um tema literalmente estratégico e urgente. $\mathrm{O}$ Brasil, seguindo a tendência mundial, após a Conferência de Estocolmo, em 1972, em razão da constatação da deterioração ambiental e da limitabilidade do uso dos recursos naturais, ou seja,

\footnotetext{
${ }^{1} \mathrm{O}$ art. 81, parágrafo único, I, da Lei 8.078/90, que instituiu o Código de Defesa do Consumidor, traz de forma inovadora o conceito legal de direito difuso, sendo aplicado para todo o microssistema de direito coletivo. Direitos difusos constituem-se em direitos transindividuais, cujo interesse abrange um número indeterminado de pessoas unidas por uma situação de fato. Ou seja, ultrapassam a esfera de um único indivíduo, caracterizados principalmente por sua indivisibilidade, onde a satisfação do direito deve atingir a uma coletividade indeterminada, porém, ligada por uma circunstância de fato.
} 
com a crise ambiental e o desenvolvimento econômico desregrado, buscou a necessidade de se garantir uma proteção jurídica ao meio ambiente com qualidade de vida ao ser humano.

A partir da promulgação da Constituição Federal de 1988, o meio ambiente passou a ser um bem tutelado constitucionalmente, dentro do Capítulo VI, do Título VIII, "Da Ordem Social", consubstanciado no artigo 225 , com seus parágrafos e incisos, que exercem o papel norteador do meio ambiente. Nessa função norteadora, a Carta Magna possui um complexo teor de direitos, mensurado pela obrigação do Estado e da sociedade na garantia de um meio ambiente ecologicamente equilibrado, já que se trata de um bem de uso comum do povo e que deve ser preservado para a presente e futuras gerações.

A historicidade das Constituições Brasileiras, anteriores à de 1988, revela que não havia nelas preocupação com a tutela ambiental de forma específica e globalizante, apenas abordavam os recursos naturais sob o enfoque econômico, utilitarista e, nunca, sob a ótica protecionista. A expressão meio ambiente foi utilizada pela primeira vez e definitivamente consagrada pela Constituição Federal de 1988, preservando a natureza em todos os seus elementos essenciais à vida do ser humano e à manutenção do equilíbrio ecológico, baseado na qualidade de vida, como uma forma de direito fundamental da pessoa humana.

Embora a Constituição Federal de 1988 tenha garantido a todos o direito ao meio ambiente ecologicamente equilibrado, sendo erigido à categoria de direito fundamental, o modelo vigente precisa ultrapassar os limites das normas e concretizá-las no mundo fático, buscando o alcance almejado para a efetivação de um verdadeiro Estado de Direito Ambiental, para que se obtenha o equilíbrio necessário entre a atividade econômica e a preservação do meio ambiente, com a consequente sobrevivência da própria vida, em todas as suas formas.

\section{REFERÊNCIAS:}

ANTUNES, Paulo de Bessa. Direito Ambiental. 15a. ed. São Paulo: Atlas, 2013.

BELCHIOR, Germana Parente Neiva. Hermenêutica Jurídica Ambiental. 3ạ ed. São Paulo: Saraiva, 2011.

LEITE, José Rubens Morato e AYALA, Patryck de Araújo. Dano Ambiental: do individual ao coletivo extrapatrimonial. 5a.. ed. São Paulo: Revista dos Tribunais, 2012.

MILARÉ, Édis. Direito do ambiente: a gestão ambiental em foco: doutrina, jurisprudência, glossário. 7ạ. ed. São Paulo: Revista dos Tribunais, 2011. 
SARLET, Ingo Wolfgang. A Eficácia dos Direitos Fundamentais: uma teoria dos direitos fundamentais na perspectiva constitucional. $11^{\underline{a}}$ ed. rev. atual. Porto Alegre: Livraria do Advogado Editora, 2012.

TRENNEPOHL, Terence. Direito Ambiental. 4ạ. ed. Bahia: Editora Juspodivm, 2009.

THOMÉ, Romeu. Manual de Direito Ambiental. 2a․ Ed. Bahia: Editora Juspodivm, 2012. 